\title{
Análisis de factores de expansión del gasto en pensiones en el Régimen de Invalidez, Vejez y Muerte de la Caja Costarricense de Seguro Social
}

Analysis of the factors of expansion of spending on pensions in the regime of Invalidity, Old Age and Death of the Costa Rican Cover of Social Security

\section{José Fulvio Sandoval Vásquez}

Escuela Ciencias de la Administración, Universidad Estatal a Distancia, Costa Rica

jsandoval@uned.ac.cr

\section{Gustavo Hernández Castro}

Escuela Ciencias de la Administración, Universidad Estatal a Distancia, Costa Rica

ghernandezc@uned.ac.cr

Recibido: 20/05/2019 • Aceptado: 13/11/2019

\section{Resumen}

En este artículo se analiza, desde un punto de vista macroeconómico, las opciones que tiene Costa Rica para controlar el crecimiento del gasto en pensiones en relación con el Producto Interno Bruto (PIB), en el caso del Régimen de Invalidez Vejez y Muerte (RIVM) administrado por la Caja Costarricense de Seguro Social (CCSS). Con esta finalidad se desarrolla un modelo econométrico que descompone la razón gasto en pensiones a PIB en cuatro factores (demografía, mercado de trabajo, elegibilidad y generosidad). La estimación del modelo 
proporciona los coeficientes de elasticidad de cada factor respecto a la razón gasto en pensiones al PIB, los cuales permiten analizar la importancia de cada elemento y establecer opciones de política para la contención del gasto en procura de la sostenibilidad del RIVM por el lado del gasto.

Palabras clave: sostenibilidad actuarial, tasa de reemplazo, radio de soporte.

\begin{abstract}
This article analyzes, from a macroeconomic point of view, the options that Costa Rica has to control the growth of pension spending in relation to the Gross Domestic Product (GDP), in the case of the regime of invalidity, old-age and deathpensions administered by the Costa Rican Social Security Fund (CCSS). To this end, an econometric model is developed that decomposes the ratio of pension expenditure to GDP into four factors (demography, labor market, eligibility and generosity). The estimation of the model provides the elasticity coefficients of each factor with respect to the ratio of pension expenditure to GDP, which allow analyzing the importance of each element and establishing policy options for the containment of expenditure in order to ensure the sustainability of the RIVM by expense side.
\end{abstract}

Key words: actuarial sustainability, replacement rate, support radio.

\title{
INTRODUCCIÓN
}

Los sistemas de pensiones están diseñados para proporcionar ingresos cuando los trabajadores pierden su capacidad de trabajo debido a la edad avanzada o discapacidad permanente; asimismo, cuando se reducen los ingresos del hogar debido al fallecimiento de una de las principales fuentes de entradas económicas de una familia. El envejecimiento necesariamente termina por imponer una cesación en el trabajo o, al menos, una disminución importante en los ingresos por actividades económicas. En la vejez las necesidades materiales se sostienen a través de la jubilación, la ayuda familiar, las redes sociales de apoyo, la caridad pública y, en los sectores pudientes, con el ahorro y las inversiones acumuladas. 
En la Edad Media las condiciones físicas eran necesarias para la guerra, de manera que alguien que, conforme su edad, se iba debilitando y no podía luchar, pasaba a depender de la voluntad de las familias o al gran grupo de indigentes que se había conformado; solo las personas adineradas de edad avanzada tenían la posibilidad de retirarse a algún monasterio o bien, ser atendidos por familiares y sirvientes hasta sus últimos días (Martínez, Polo, \& Carrasco, 2002). Bajo estas circunstancias, las personas de avanzada edad que no tenían dinero para su subsistencia básica, representaban un problema para la sociedad y para las propias familias que debían ganar su sustento y el de los ancianos de la época (Arquiola, 1995).

Según Pène (1999) y Kibut (2004), las pensiones por jubilación iniciaron en Francia; inicialmente, se otorgaron a los marineros con el objetivo de garantizar su supervivencia en la vejez y evitar que se convirtieran en piratas. Posteriormente, Otto Von Bismark, llevó este concepto a Alemania y fue aprobado por el Emperador Guillermo I. Adicionalmente, en Bélgica y Holanda los funcionarios de gobierno fueron beneficiados con pensiones en 1844.

Después de los marineros, otros segmentos de la población se beneficiaron de la jubilación, principalmente aquellas personas sin tierras y cualquier otro tipo de riqueza, quienes podían ejercer algún medio de presión sobre los gobernantes; ellos fueron, inicialmente, los militares y los obreros. La industrialización, que consistió en traslado de trabajadores de zonas rurales a urbanas, permitió que otras clases de trabajadores pudieran acceder al sistema de pensiones (Pène, 1999).

Para Mesa Lago (2005) en América Latina, los países pioneros en introducir modelos de pensiones fueron Uruguay, Argentina, Chile, Cuba, Brasil y Costa Rica, quienes establecieron sistemas de seguridad social durante las décadas de los veinte y los treinta del siglo pasado. Asimismo, un siguiente grupo lo conformaron Panamá, México, Perú, Colombia, Bolivia, Ecuador y Venezuela, quienes implantaron sus programas principalmente en las décadas de los cuarenta y cincuenta, logrando una cobertura y desarrollo medio en sus sistemas. Finalmente, en las décadas de los sesenta y setenta del siglo pasado, países como Paraguay, República Dominicana, Guatemala, El Salvador, Nicaragua, Honduras y Haití, también introdujeron sistemas de seguridad social. 
Al presente, los sistemas de pensiones afontan la realidad de una América Latina que envejece en forma acelerada; en el 2010, el porcentaje de las personas mayores a 65 años representaba $6.8 \%$ de la población. Las estimaciones para el 2050 señalan que este porcentaje será equivalente al $19.8 \%$ del total de habitantes de esta región. Dado lo anterior, en el 2050 habitarán más de 140 millones de personas con 65 años o más; es decir, casi cuatro veces más que los 40 millones de personas en la actualidad (Banco Mundial, 2015).

En Costa Rica, los regímenes de pensiones abiertos como el Régimen de Invalidez, Vejez y Muerte (RIVM) de la Caja Costarricense de Seguro Social (CCSS), la Junta de Pensiones del Magisterio Nacional (JUPEMA) y el régimen del Poder Judicial — para citar los más importantes- se crearon en coyunturas sociales distintas a las actuales, con parámetros de cotización, esperanza de vida y crecimiento de la población joven que eran favorables para regímenes de reparto. Sin embargo, al igual que en el resto de América Latina, la sostenibilidad financiera de estos regímenes se ha visto amenazada por los cambios demográficos ocurridos en las últimas décadas, principalmente por cuatro factores (Banco Mundial, 2015; WorldLife, 2017):

- Los diferentes tamaños de las generaciones que cotizan, como consecuencia del envejecimiento de la población.

- La mayor esperanza de vida lograda debido a los avances de la medicina y al entorno más sano.

- El declive en la tasa de natalidad, debido a la nueva dinámica social.

- Los cambios estructurales en el mercado de trabajo, que han aumentado la tasa de desempleo y el trabajo informal.

Se estima que en el proceso de transición de la población que enfrenta Costa Rica, esta última deje de crecer alrededor del 2050, cuando se alcazará la cifra de casi seis millones de habitantes. La población adulta mayor en Costa Rica ha venido creciendo tanto en términos absolutos como relativos. Según el Instituto Nacional de Estadística y Censos (INEC, 2013), para el 2011 había 364333 personas adultas mayores, 142576 más que en el 2000. 
Al considerar esta coyuntura, en el presente trabajo se analiza la flexibilidad que posee el Estado costarricense para limitar el gasto en pensiones, principalmente en el RIVM, como proporción del Producto Interno Bruto (PIB). Esto como una medida adicional para otorgar solvencia y sostenibilidad al régimen de pensiones indicado. Si bien existen propuestas para incrementar los ingresos del RIVM y para modificar los parámetros del régimen, como posponer por edad de retiro de las personas, bajar el beneficio recibido, aumentar las primas de cotización, establecer nuevas fuentes de ingreso, entre otras; este artículo se concentra en analizar los factores de expansión del gasto y sus posibilidades de contención, como uno de los aspectos que se abordan en una investigación más amplia que realiza la Escuela de Ciencias de la Administración de la Universidad Estatal a Distancia (UNED), en relación con la problemática del sistema de pensiones en Costa Rica y las opciones para lograr su equilibrio y sostenibiliad en el largo plazo.

Además de esta introducción, el artículo se divide en seis secciones adicionales. En la segunda sección, se describe la integración actual del Sistema Nacional de Pensiones (SNP) del país. En la tercera sección, se caracteriza el Régimen de Invalidez, Vejez y Muerte (RIVM) que administra la Caja Costarricense de Seguro Social (CCSS). En la cuarta sección, se presenta la problemática financiera que enfrenta el RIVM durante las dos primeras décadas del siglo XX. En la quinta sección, se describe el procedimiento metodológico para el desarrollo del modelo econométrico utilizado para valorar los factores de expansión de la razón gasto en pensiones al PIB. La sexta sección presenta los resultados de la corrida del modelo y se discuten estos resultados bajo la óptica de contención del gasto del RIVM. Finalmente, la sétima sección contiene las principales conclusiones del estudio.

\section{EL SISTEMA NACIONAL DE PENSIONES ${ }^{1}$}

En Costa Rica, los orígenes de los sistemas de pensiones datan del siglo XIX con la promulgación de la Ley de Pensiones para Maestros Titulados de 1886, que es la base del actual Fondo de Pensiones y Jubilaciones del Magisterio Nacional (FPJMN). Posteriormente, en 1947 surgió el principal

1 Con base en información del Informe Arias, Barboza y Ramírez (2016), conocido como el Informe de la UCR, y de las páginas de la SUPEN y de MIDEPLAN. 
régimen de pensiones de la actualidad, el régimen de pensiones de Invalidez, Vejez y Muerte (RIVM) de la CCSS; sin embargo, ya existían en el país otros regímenes de pensiones específicos para sectores de empleados públicos y, posteriormente, a 1947 se crearon otros más (Arias, Barboza, \& Ramírez, 2016).

Con la promulgación de la Ley de Protección al Trabajador (LPT) del 24 de enero de 2000, se estructuró el actual Sistema Nacional de Pensiones (SNP) que consta de cuatro pilares (la Figura 1 sintetiza la conformación actual del SNP).

- $\quad$ El Régimen de Pensión Contributiva Básica.

- El Régimen Obligatorio de Pensiones Complementarias.

- El Régimen Voluntario de Pensiones.

- $\quad$ El Régimen de Pensiones no Contributivas.

Los sistemas multipilares de pensiones como el costarricense, se componen de regímenes de reparto y de capitalización individual, los cuales financian la pensión final del trabajador.

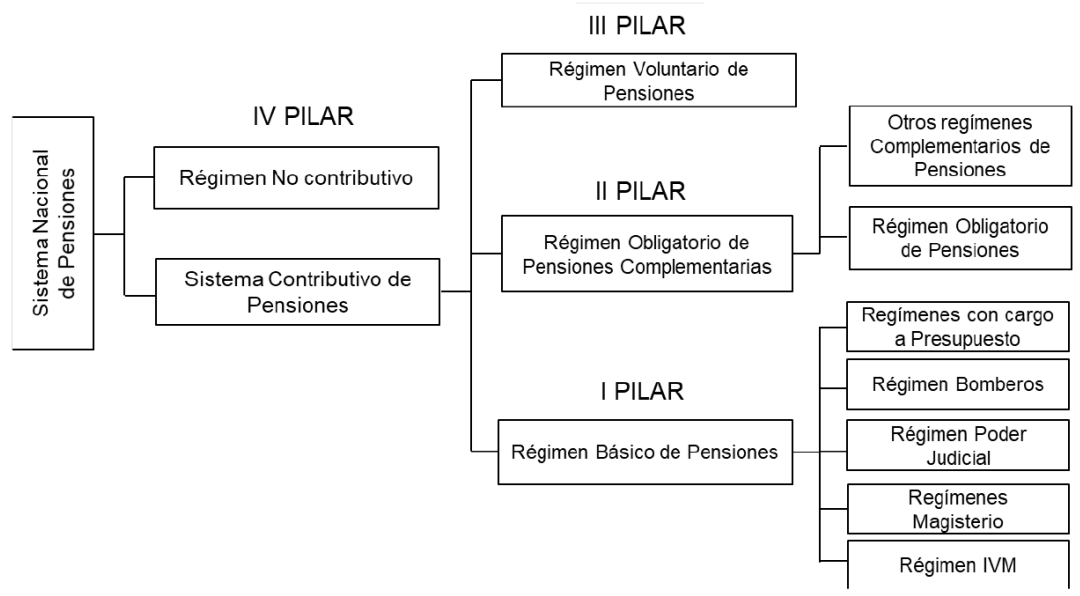

Figura 1. Componentes del Sistema Nacional de Pensiones

Fuente: Estudio actuarial del seguro de IVM de la CCSS. UCR (2016). 
En un régimen de reparto, las contribuciones o cuotas que aportan el trabajador, patrono y Estado, se depositan en un fondo común que permite pagar las pensiones de la generación pensionada anterior. Además, cuando se agotan los fondos; es decir, cuando las contribuciones, más los rendimientos que genera el fondo y el propio fondo, no son suficientes para cumplir con las pensiones corrientes, el Estado debe asumir el déficit del sistema.

Por otra parte, en el régimen de capitalización individual, existe una entidad operadora de pensiones que registra los aportes que cada trabajador realiza (incluyendo los patronales y del Estado, si los hubiera), en una cuenta individual que es administrada por la operadora durante la vida laboral de la persona. Esto con la finalidad de generar rendimientos e intereses que al final se utilizan para pagar la pensión del beneficiario.

Este tipo de esquema multipilar fue promovido por el Banco Mundial en la década de 1990 como mecanismo para disminuir la presión financiera de los regímenes de reparto (Banco Mundial, 1997). Dentro de estos sistemas cada pilar se caracteriza por diferencias en variables o parámetros, como la edad de retiro, el porcentaje de cotización, el número de cuotas necesarias para tener derecho a la pensión, el salario de referencia para el cálculo de la pensión y la tasa de reemplazo o cantidad de dinero que recibirá la persona cuando se jubile en relación con el último sueldo o salario que percibía cuando trabajaba.

En Costa Rica, el primer pilar básico contributivo (Régimen Básico de Pensiones), se financia con aportes de los beneficiarios, patronos y del Estado y presenta un esquema de prestaciones o beneficio definido; es decir, se establece a priori el tipo y el monto de la pensión que recibirán los beneficiarios. Este pilar constituye el principal componente del SNP y actualmente está integrado por los siguientes regímenes:

1. Invalidez, Vejez y Muerte (IVM) de la CCSS (asalariados e independientes). Creado por la Ley de Creación de la CCSS el 22 de octubre de 1943 y entró en operación a partir del año 1947.

2. Capitalización Colectiva del Magisterio Nacional. Régimen que es administrado por la Junta de Pensiones y Jubilaciones del Magisterio Nacional (JUPEMA). 
3. Transitorio de Reparto Magisterio Nacional (Leyes 2248, 7268 y 7531). Régimen administrado por la Junta de Pensiones y Jubilaciones del Magisterio Nacional, pero con cargo al Presupuesto Nacional.

4. Pensiones y Jubilaciones del Poder Judicial. Régimen administrado por el Poder Judicial.

5. Pensiones y Jubilaciones de Bomberos Permanentes. Régimen administrado por el Instituto Nacional de Seguros (INS).

6. Otros regímenes administrados por la Dirección Nacional de Pensiones (DNP) con cargo al Presupuesto Nacional. ${ }^{2}$

En general, el primer pilar opera por medio de un sistema de capitalización colectiva o de reparto, en el cual el fondo de pensiones es propiedad colectiva (no individual) de todos los afiliados. Asimismo, coexisten distintos modelos de financiamiento y no existe uniformidad, lo cual no permite establecer una relación aporte/beneficio de los afiliados (MIDEPLAN, 2016). Algunos de estos regímenes se encuentran cerrados por Ley (es decir, no aceptan más pensionados); por ejemplo, el régimen de bomberos y el régimen original del Magisterio.

De todos los regímenes que integran el primer pilar, el RIVM de la CCSS es el más importante, tanto en lo referente al número de cotizantes activos, como de pensionados. En número de pensionados le sigue en orden de importancia el régimen Transitorio de Reparto del Magisterio Nacional.

El segundo pilar consiste en un régimen de capitalización individual que otorga una pensión complementaria de contribución definida (es decir, se cotiza con un porcentaje fijo del salario), obligatoria y solo disponible para la población asalariada. Los aportes los registra y controla la CCSS y los administran Operadoras de Pensiones Complementarias (OPC) con libertad para que cada trabajador elija entre ellas.

2 Son regímenes contributivos administrados por la Dirección Nacional de Pensiones (DNP) con cargo al Presupuesto Nacional. Entre estos se pueden citar: Hacienda (que incluye diputados); Obras Públicas y Transportes; empleados de Comunicaciones (y excepciones); empleados del Ferrocarril al Pacífico; Músicos de Bandas Militares y Registro Nacional. 
Dentro de este pilar existen dos tipos de pensiones complementarias obligatorias, las creadas por la Ley de Protección al Trabajador (LPT, Ley No. 7983 del 24 de enero de 2000) y las que existían previamente a la LPT. $^{3}$

Las Pensiones complementarias creadas antes de la LPT están constituidas por seis fondos complementarios obligatorios de capitalización colectiva asociados y gestionados por las siguientes instituciones: Fondo de retiro de la Caja Costarricense de Seguro Social, Fondo de retiro del Banco Nacional de Costa Rica, Fondo de retiro del Instituto Costarricense de Turismo (ICT), Fondo de retiro del Banco Crédito Agrícola de Cartago y Fondo de retiro del Banco de Costa Rica (MIDEPLAN, 2016).

El tercer pilar también es un régimen complementario, pero, a diferencia del segundo que es obligatorio, este es voluntario. Es un régimen de capitalización individual y está disponible para cualquier persona ocupada o no; asimismo, también es administrado por las operadoras de pensiones. En este, los aportes son libres y corresponde al afiliado decidir el monto de ellos, que pueden ser en colones o en dólares y, además, el afiliado puede realizar aportes extraordinarios en el momento en que lo desee y cuenta con incentivos fiscales como la exoneración del impuesto sobre la renta.

Los beneficios del régimen del tercer pilar pueden disfrutarse una vez que el afiliado cumpla 57 años de edad; sin embargo, es posible el retiro anticipado parcial o total de los recursos acumulados en las cuentas individuales, una vez que el afiliado haya cotizado durante, al menos, 66 meses (caso en que debe devolver parte de los incentivos fiscales a que tuvo derecho). También, es posible el retiro de los recursos acumulados antes de la edad reglamentaria por invalidez, enfermedad terminal o muerte del afiliado. Los planes de beneficios de este régimen comprenden la renta vitalicia, la renta permanente y la renta temporal (MIDEPLAN, 2016).

En los sistemas de pensiones basados en esquemas de protección multipilar, como en el caso costarricense, la protección económica previsional del régimen básico es fortalecida por el segundo y tercer pilar complementarios. Por tanto, el segundo y tercer pilar contribuyen al levantamiento de

3 Los planes de pensiones complementarias se crearon con la Ley No. 7523 del 7 de julio de 1995, Régimen Privado de Pensiones Complementarias y Reformas a la Ley Reguladora del Mercado de Valores y del Código del Comercio. Asimismo, con dicha normativa se creó la Superintendencia de Pensiones (SUPEN). 
la tasa de reemplazo que proporciona el régimen básico. Como se indicó, la tasa de reemplazo o tasa de sustitución se refiere a la cantidad que recibe una persona cuando se jubila en comparación con el último sueldo que percibía cuando trabajaba.

Finalmente, el cuarto pilar corresponde a los regímenes no contributivos administrados por la Dirección Nacional de Pensiones (DNP) del Ministerio de Trabajo y Seguridad Social ${ }^{4}$ y el Régimen no Contributivo de Pensiones (RNC) administrado por la CCSS.

EI RNC de la CCSS busca auxiliar solidariamente a la población que se encuentra en situación de pobreza y que no cotiza a los regímenes contributivos de pensiones. Los recursos para este fondo provienen del Fondo de Desarrollo Social y Asignaciones Familiares (FODESAF), de la Junta de Protección Social (JPS), así como de transferencias directas del Ministerio de Hacienda. Este régimen cubre a la población adulta mayor, a personas con discapacidad permanente que les impiden trabajar, en situación de pobreza extrema y a personas menores de edad en situación de riesgo (MIDEPLAN, 2016).

En esencia, el cuarto pilar contribuye a universalizar el primer pilar entre quienes alcanzaron los 65 años sin contar con una pensión contributiva y está orientado a personas en condiciones de pobreza.

\section{EL RÉGIMEN DE PENSIONES DE INVALIDEZ, VEJEZ Y MUERTE (RIVM) DE LA CCSS}

EI RIVM que administra la CCSS es un seguro social de beneficio definido, obligatorio para todos los trabajadores asalariados e independientes. Como su nombre lo indica, sus coberturas son por invalidez, vejez y muerte. Fue creado por la Ley de Creación de la CCSS del 22 de octubre de 1943 y entró en operación a partir del año 1947. El régimen obedece a los principios de universalidad, solidaridad, obligatoriedad, igualdad, equidad y subsidiariedad. En este caso, el principio de solidaridad debe entenderse como solidaridad intra e intergeneracional.

4 Estos regímenes tienen cargo al presupuesto nacional y son los siguientes: Beneméritos, de Derecho Guardia Civil, Pensiones de Gracia y Ley General de Pensiones, Premios Magón, de Expresidentes, de Guerra Excombatientes, Prejubilados INCOP y de Prejubilados INCOFER (MIDEPLAN, 2016). 
Es administrado por la CCSS con autonomía del Poder Ejecutivo y de la Autoridad Presupuestaria. Las fuentes de financiamiento del RIVM provienen de los siguientes rubros:

1. Aportes obreros, patronales y del Estado.

2. Las reservas creadas para ese fin.

3. Hasta un $15 \%$ sobre las utilidades de las empresas públicas del Estado.

4. Ingresos provenientes de la inversión de sus reservas.

5. Ingresos de alquileres, multas, donaciones o legados.

Este régimen es el principal componente de la pensión en el SNP del país y constituye el régimen de universalización de la pensión como mecanismo de cumplimiento del derecho humano a la seguridad social. Como se indicó, este régimen consiste en un fondo de capitalización colectiva en el cual las contribuciones corrientes tripartitas del trabajador, patrono y Estado financian las pensiones actuales (reparto) y a la vez alimentan un fondo de reserva que se capitaliza (fondo de capitalización). Por su carácter público y colectivo, se basa en cuatro principios fundamentales: (1) solidaridad, (2) redistribución de riqueza, (3) riesgos compartidos y (4) financiamiento colectivo.

En el año 2014, el RIVM adoptó el sistema de financiamiento de primas escalonadas; en este caso, los aportes tripartitos al fondo se establecen mediante cotizaciones sobre el ingreso o salarios de los trabajadores, donde los trabajadores contribuyen con un $2.84 \%^{5}$, los patronos con un $5.08 \%$ y el Estado con el $0.58 \%$, todo lo cual suma una contribución o cotización del $8.50 \%$ del ingreso o salario devengado por el trabajador. ${ }^{6}$

5 Debido a la reforma al Reglamento del Seguro de Invalidez, Vejez y Muerte (IVM) publicada en La Gaceta del 22 de junio de 2017, se realizó un aumento de $0.50 \%$ al monto de aporte obrero al RIVM, que lo pasa de un $2.84 \%$ a un $3.34 \%$ a partir del mes de julio de 2017.

6 En el caso de los trabajadores independientes, existen cinco categorías de contribución en función del nivel de ingreso del trabajador comparado con el nivel del salario mínimo legal de un trabajador no calificado genérico. 
La base mínima de contribución (BMC) sobre el salario mínimo -ingreso mínimo de referencia para cotizar sobre el salario mínimo- se ha estado incrementando, siendo el $57.70 \%$ del salario mínimo en enero de 2014 ; $64.75 \%$ en octubre de $2014 ; 71.8 \%$ en octubre de $2015 ; 78.85 \%$ en octubre de 2016. Asimismo, se ha establecido que llegue al $85.90 \%$ en octubre de $2017 ; 92.95 \%$ en octubre de 2018 y el $100 \%$ del salario mínimo a partir de octubre de $2019 .^{7}$

Los requisitos para acogerse a la pensión ordinaria por vejez establecen la edad de 65 años o más y contar con 300 cotizaciones. Sin embargo, la pensión por vejez se puede anticipar con los siguientes requisitos. ${ }^{8}$

1. Hombres: 462 cuotas mensuales, edad 61 y 11 meses, el número de cuotas se reduce conforme aumenta la edad hasta 300 a los 65 años de edad.

2. Mujeres: 450 cuotas mensuales a los 59 años y 11 meses; el número de cuotas se reduce hasta 300 a los 65 años de edad.

EI RIVM también establece la posibilidad de acceder a una pensión reducida bajo los siguientes requisitos: ${ }^{9}$

1. Hombres: 62 años con al menos 300 cuotas.

2. Mujeres: 60 años con al menos 300 cuotas.

Asimismo, se puede acceder a una pensión proporcional, para lo cual se debe tener la edad de 65 años o más y de entre 180 a 299 cuotas mensuales. Además, el artículo 26 de la Ley de Protección al Trabajador (LPT) permite un retiro anticipado por RIVM, para lo cual, la edad mínima es de 57 años para hombres y mujeres y el período máximo de anticipación es de cinco años. Sin embargo, existe la condición de que el afiliado cuente con un Plan Voluntario de Pensión complementaria donde haya acumulado el costo del anticipo.

7 Artículo No. 26 de la sesión de Junta Directiva de la CCSS No. 8682 del 289 de noviembre de 2013.

8 En el artículo No. 31 de la sesión No. 8803 del 1 de octubre del 2015 la Junta Directiva de la CCSS acordó eliminar gradualmente la opción de anticipar.

9 El costo del anticipo para ambos sexos es de 1.75 por trimestre anticipado. Asimismo, esta opción está condicionada a que el monto resultante de la pensión sea mayor a la mínima. 
El beneficio o monto de la pensión por vejez se calcula según el salario de referencia el cual considera el promedio de los últimos 240 salarios o ingresos mensuales devengados (20 años) y cotizados por el asegurado (o de los salarios cotizados cuando son menores de 240), actualizados con el Índice de Precios al Consumidor (IPC). La tasa de reemplazo varía del $43 \%$ al $52.5 \%$ del salario de referencia, dependiendo del rango del salario. El tope máximo de pensión es de menos de $\phi 2$ millones.

En el RIVM, los derechos sobre la pensión a terceros son esencialmente relacionados con atender a los niños y adolescentes en edad escolar y las personas con alguna discapacidad. Las pensiones mínimas son equivalentes a lo requerido para no estar en condición de pobreza, por lo que es un sistema fundamental en la atención de la población adulta mayor, sus condiciones y calidad de vida. ${ }^{10}$

A finales del año 2016 para el RIVM cotizaban más de 1.5 millones de trabajadores y se encontraban registrados 83442 patronos y el Estado. El régimen pagaba las pensiones a 225.984 beneficiarios (51 400 por invalidez, 115135 por vejez y 59449 por muerte) y su cobertura contributiva era de un $59.7 \%$ de la población trabajadora (Población Económicamente Activa, PEA), en donde un $63.7 \%$ era para los asalariados y el $52.2 \%$ para los trabajadores independientes (Arias, Barboza, \& Ramírez, 2016). De acuerdo con la información de la CCSS, la cobertura por rama de actividad económica es la siguiente:

- $\quad$ El $30.05 \%$ en servicio doméstico (15\% como asalariadas).

- $\quad$ El $52.48 \%$ en construcción, actividades artísticas y servicios.

- $\quad$ El $65 \%$ en agricultura, comercio, actividades inmobiliarias y servicios de comida.

- El $79.56 \%$ en industria manufacturera, servicios administrativos, agua, comunicaciones y salud.

10 En el Reglamento de IVM se establecen los parámetros para fijar los montos de las pensiones mínimas y máximas. El monto de la pensión mínima está definido en el artículo 29 , el cual establece que no podrá ser menor que el $50 \%$ de la base mínima contributiva. Asimismo, la pensión máxima se define en ese mismo artículo y corresponde a la Junta Directiva su establecimiento considerando el número de meses y trimestres postergados (artículo 29 y Transitorios VII y VIII). 
- $\quad$ El $97.45 \%$ en sector público y financiero.

Entre los factores que limitan la extensión de la cobertura contributiva, la CCSS ha señalado los siguientes: el costo del aseguramiento, las modalidades de aseguramiento, las condiciones del mercado laboral, el uso de formas no contributivas de aseguramiento, la prestación de servicios de trabajadores con patronos morosos y las barreras en la inscripción.

Según los datos de la CCSS, la morosidad en el RIVM es baja y ha presentado una tendencia decreciente desde el año 2014 al primer trimestre de 2017, donde el indicador de morosidad pasó del $0.78 \%$ en el 2014 a $0.42 \%$ en el primer trimestre de 2017 . Asimismo, el saldo de la cartera total de inversiones del IVM, al 31 de mayo de 2017, muestra que el $95.38 \%$ de las inversiones se encuentra en títulos valores ( $\phi 1914734.09$ millones) y el $3.10 \%$ en préstamos hipotecarios ( $\phi 62164.85$ millones).

La solidez actuarial de un sistema de reparto como el de RIVM descansa en el crecimiento de la población, la producción nacional y los ingresos reales de la sociedad, de forma que requiere que siempre haya más personas jóvenes que adultos mayores en una población que crece. El economista Samuelson (1958) señaló que, si los ingresos reales de un país crecían alrededor del tres por ciento anual, la base imponible sobre la que descansan las prestaciones en cualquier período sería mayor que las contribuciones que ha pagado históricamente la generación ya jubilada. Por tanto, la sostenibilidad del sistema dependería, entre otros factores, del crecimiento de la fuerza de trabajo y de los ingresos reales de la nación.

\section{PROBLEMÁTICA FINANCIERA DEL RÉGIMEN DE INVALIDEZ, VEJEZ Y MUERTE}

La coyuntura demográfica presente en el país, caracterizada por una tasa de fecundidad que cubre básicamente el reemplazo de la población, con un creciente envejecimiento de la población y una alta esperanza de vida, hace obligatorio para la generación actual revisar y ajustar estos regímenes de pensiones del primer pilar en procura de su sostenibilidad económica en el tiempo (WorldLife, 2017).

Si bien la riqueza en el país ha crecido en los últimos 20 años, también se han incrementado las desigualdades en los ingresos de la población, 
situación que afecta la base contributiva de los regímenes de reparto, en especial del RIVM. Por tanto, de no efectuarse mejoras en el actual RIVM, un número cada vez más grande de personas mayores corre el riesgo de sufrir una pobreza relativa, por causa del colapso en el régimen o al tener que reducirse el monto de la pensión a la que tienen derecho.

Ciertamente, como señaló Samuelson en 1967, el rápido crecimiento de la producción y la productividad pueden absorber parte de la tensión financiera del RIVM; pero si el crecimiento económico se reduce, el desequilibrio generacional obliga a tomar decisiones para mantener la sostenibilidad económica, las cuales se enmarcan dentro de las siguientes opciones:

1. Los miembros o trabajadores activos, patronos y Estado de la generación actual y generaciones siguientes, tendrán que aumentar su contribución al régimen de pensiones, en relación con la contribución de los miembros del conjunto de sus predecesores, a fin de pagar las pensiones de estos últimos.

2. Reducir la pensión que recibirían los miembros de la generación actual y generaciones siguientes, para que las tasas de cotización o contribución sobre los sueldos y salarios, que pagan los contribuyentes actuales y siguientes, no tengan que aumentar.

3. Aumentar la tasa de contribución sobre sueldos y salarios para la generación trabajadora activa (incluyendo patronos y Estado) y recortar las pensiones de la generación pensionada o pasada y futura, hasta encontrar una solución a la situación de sostenibilidad financiera del régimen de pensiones, basada en el "sacrificio compartido" entre generaciones de trabajadores (activa, pensionada y futuros beneficiarios).

Debe recordarse que los sistemas de pensiones públicas basados en el reparto reflejan un compromiso entre generaciones de trabajadores, donde cada generación hace una aportación y cada una recibe un beneficio.

En el año 2005, el Programa Estado de la Nación indicó que los problemas financieros que presentaba el RIVM en ese período se debían fundamentalmente a cuatro aspectos:

1. Factores demográficos. 
2. La dinámica del mercado laboral.

3. Aspectos de diseño del régimen.

4. Niveles de eficiencia administrativa.

A quince años de ese diagnóstico, los mismos factores vuelven a tomar relevancia en la actual situación financiera y de sostenibilidad del RIVM. Como se ha indicado, el cambio en el perfil demográfico es el factor más relevante que condiciona la situación actual: ha aumentado la esperanza de vida, ha disminuido la mortalidad infantil y se ha reducido el número de hijos por familia; de manera que el país mantiene actualmente la tasa de fecundidad por reemplazo; es decir, las personas que nacen alcanzan a reemplazar a las que mueren.

Sauma (2013) indicó que para caracterizar la situación que atraviesa el RIVM, además de considerar los cambios demográficos que reflejan los censos de población de los años 2000 y 2011, deben considerarse los siguientes aspectos:

- Los incrementos en las pensiones mínimas del RIVM (que reciben buena parte de los pensionados), lo cual ha incrementado el gasto del régimen respecto a los ingresos.

- Las resoluciones de la Sala Constitucional, que han otorgado derechos de pensión que reglamentariamente no se permitían y que entran en tensión con los límites o condiciones impuestos en virtud de reglas actuariales.

- El impacto del incremento en el número de trabajadores independientes asegurados, cuya contribución por lo general es menor al régimen en relación con los beneficios que posteriormente reciben.

- La divergencia que existe en el ingreso mínimo contributivo (con el cual se asegura una proporción importante de trabajadores) y el monto mínimo de la pensión, generando un beneficio adicional para quienes contribuyen con lo mínimo.

- La falta de implementación de lo dispuesto por la LPT en su artículo 78 en lo referente a los recursos adicionales provenientes de las 
utilidades de las empresas públicas que podrían nutrir el régimen, así como a la universalización de la cobertura a los sectores de trabajadores no asalariados en condiciones de pobreza.

- Una amenaza adicional para la estabilidad del RIVM se presenta con el creciente desempleo que ha debilitado las bases contributivas de ese régimen; según INEC, la tasa de desempleo ha evolucionado de un $7.29 \%$ en el año $2010 ; 7.66 \%$, en $2011 ; 7.77 \%$, en $2012 ; 8.5 \%$, en 2013 ; $9.7 \%$, en 2014 ; $9.6 \%$, en 2015 ; y $9.5 \%$ en 2016 , hasta un $11.4 \%$ en el tercer trimestre de 2019.

En relación con los pronósticos de sostenibilidad financiera del RIVM, para el año 2004 la Gerencia de Pensiones de la CCSS presentó un estudio actuarial que describía la sostenibilidad en tres momentos en el tiempo:

Primer momento. Cuando los aportes o cotizaciones tripartitas (trabajadores, patronos y Estado) sobre salarios no son suficientes para financiar las pensiones del momento y deben complementarse con parte de los rendimientos que genera las inversiones realizadas con el fondo de reserva. ${ }^{11}$

Segundo momento. Cuando las cotizaciones por salarios que ingresan al régimen más los rendimientos del fondo de reserva no son suficientes para cumplir con las pensiones corrientes, de manera que el pago de las pensiones corrientes implica utilizar el propio fondo de reserva. ${ }^{12}$

Tercer momento. Cuando las contribuciones tripartitas corrientes sobre salarios más el propio fondo de reserva se agota para cumplir con las pensiones corrientes, de manera que el déficit debe cubrirse con cargo al Presupuesto Nacional.

11 En este momento las contribuciones que ingresan al régimen por la generación cotizante, no son suficientes para pagar las pensiones de la generación anterior jubilada, de manera que el déficit de reparto debe cubrirse con los intereses que genera la inversión de las reservas construidas en las décadas pasadas, cuando las cotizaciones cubrían con creces el pago de las pensiones vigentes.

12 En este caso, las contribuciones corrientes que ingresan al régimen de pensiones y los intereses que generan las reservas constituidas en las décadas anteriores, no son suficientes para pagar las pensiones de la generación anterior. Por tanto, el déficit del régimen debe cubrirse con las propias reservas existentes. 
En 2004, La Gerencia de Pensiones de la CCSS pronosticaba que los tres momentos de crisis en el régimen de IVM ocurrirían en los años 2005, 2015 y 2022, respectivamente. Posteriormente, mediante otro estudio actuarial la Organización Internacional del Trabajo (OIT), señaló como los años críticos el 2011, 2022 y 2028, respectivamente.

En esa oportunidad, para corregir la situación financiera del RIVM, las autoridades gubernamentales convocaron a un proceso de discusión y concertación de los sectores sociales y productivos dentro de una Comisión Social, que realizó diversas recomendaciones para una reforma paramétrica del RIVM en procura de su sostenibilidad financiera en el mediano y largo plazo.

A través de la reforma del año 2005 se modificaron parámetros como la tasa de cotización y el número de cuotas requeridas para la pensión, aspectos que no se reformaban desde los años 1940, cuando se crearon los seguros sociales en el país. ${ }^{13}$ En ese momento se indicaba que la reforma realizada brindaría sostenibilidad financiera al RIVM hasta el año 2050, período en el cual debería realizarse otra revisión general del régimen (Martínez, 2005).

Sin embargo, en los años 2009 y 2010 surgió nuevamente la discusión pública sobre la sostenibilidad del RIVM, se señaló que, además de la dinámica demográfica del país, uno de los principales factores que ha provocado un desfase financiero y problemas de solvencia y sostenibilidad en el RIVM fue la posibilidad de pensión anticipada creada en el año 2005.

Otras evaluaciones actuariales han alertado sobre la situación financiera del RIVM, en el Informe Final de la valuación actuarial practicada al RIVM de la CCSS por la empresa Nathal Actuarios y Consultores en julio de 2008 se indicaba la prima de cotización necesaria en ese momento era del $16.79 \%$, mientras que la prima vigente era de $7.50 \%$, de manera que el sistema vigente de aportaciones resultaba deficitario y que de mantenerse

13 Se aumentó el número de cuotas de 240 a 300 , el porcentaje de contribución tripartita de $7.5 \%$ pasó a $10.5 \%$ en un plazo de diez años; ajustando $0.5 \%$ cada cinco años, el salario de referencia paso de los 48 mejores salarios de los últimos 60 a los últimos 240 , entro otros aspectos. Por otra parte, se ampliaron ciertos beneficios como la posibilidad de retiro anticipado con un menor monto de pensión y la posibilidad de pensión reducida para quienes cotizaron y no alcanzaron las cuotas requeridas para retiro normal. 
el mismo, la suficiencia de la reserva se mantendría por los próximos 17 años (hasta el año 2025).

Por otra parte, el Informe a la Junta Directiva de la CCSS y al Comité de Vigilancia del RIVM del mes de agosto de 2014, documento ICV-2013-01; la Superintendencia de Pensiones (SUPEN) en el tema de sostenibilidad financiera y actuarial de IVM advertía a las autoridades de la CCSS que la prima total de contribución vigente, a pesar de ser escalonada, no era suficiente para la sostenibilidad financiera del régimen e indicaba que sería deficitario e insolvente en el largo plazo. En ese informe la SUPEN indicaba:

EI RIVM ha tenido que recurrir a los intereses generados por las inversiones para hacer frente a las obligaciones corrientes. Cabe recordar que la diferencia entre los ingresos y los gastos en el año 2009 se cubrió con recursos que se tenían que reinvertir, al igual que en los años 2010, 2011, 2012 y 2013, por lo que el proceso de menor capitalización de la reserva es sostenido, no es un asunto coyuntural y lo que evidencia es el problema estructural que tiene el RIVM, en donde los egresos crecen en una proporción mayor que los ingresos.

Posteriormente, el estudio actuarial del señor Torres (2015) de la Dirección actuarial de la CCSS, llegó a la conclusión de que la reserva soportaría por un plazo de seis años y se agotaría en el año 2041. Este estudio, al igual que en el Informe de la Universidad de Costa Rica (UCR; Arias, Barboza, \& Ramírez, 2016), distingue también tres escenarios: Escenario Bajo o pesimista, el RIVM es sostenible en la forma que lo conocemos hasta el año 2027; escenario medio o base el RIVM, es sostenible hasta el 2036; y en el Escenario Alto u optimista, el RIVM es sostenible al año 2042.

Con base en las recomendaciones del estudio de Torres (2015), la CCSS inicio un proceso de reformas de corto plazo en el RIVM para implementar algunas medidas para la sostenibilidad financiera del régimen, al menos, para permitir la capitalización de la reserva sin tener que utilizar parte de los rendimientos de la misma, para el pago de las pensiones corrientes. El 28 de julio de 2016, la Junta Directiva de la CCSS acordó aumentar la contribución del Estado al RIVM del $0.58 \%$ al $1.24 \%$. La segunda medida de corto plazo se concretó en julio de 2016, cuando se eliminó la modalidad de pensión anticipada con castigo en el monto y, la tercera medida, 
consiste en un aumento de un punto porcentual en los aportes de los trabajadores al RIVM, que pasaría del $2.84 \%$ al $3.84 \%$, medida que se está implementando en etapas (Avendaño, 2017).

En el estudio actuarial de la UCR (Arias, Barboza, \& Ramírez, 2016) también se ubican los tres momentos críticos antes citados en tres escenarios: bajo, medio o base y alto. Para el escenario bajo o pesimista, los momentos críticos se alcanzan en los años 2012, 2022 y 2027, respectivamente; en el escenario base, en los años 2012, 2024 y 2030, respectivamente; y, en el escenario alto u optimista, en los años 2012, 2028 y 2034, respectivamente. ${ }^{14}$ Se observa que en año 2012 se ha llegado al primer momento crítico, cuando las contribuciones que ingresan al régimen por la generación cotizante, no son suficientes para pagar las pensiones de la generación anterior jubilada, de manera que el déficit de reparto se está cubriendo con los intereses que genera la inversión de las reservas construidas en las décadas pasadas, cuando las cotizaciones cubrían con creces el pago de las pensiones vigentes.

Según la UCR, los resultados obtenidos son congruentes con el proceso de envejecimiento de la población, los altos índices de natalidad y fecundidad del período 1940-1965, el incremento en la esperanza de vida, el aumento de la cobertura promovido en las décadas de 1970 y 2000 , y el bajo crecimiento económico a partir de 2010 debido a la crisis económica iniciada en el año 2008. El Informe señala, además, otros factores como la reforma del año 2005 que concedió beneficios adicionales de pensión proporcional y reducida, los ajustes en el monto de pensión mínima en los años 2005-2009 y la falta de actualización de la base mínima contributiva en 2006-2009.

Si bien, el informe de la UCR estima que el segundo momento crítico en el IVM -cuando las contribuciones corrientes que ingresan al régimen y los intereses que genera la inversión de las reservas no son suficientes para pagar las pensiones de la generación pensionada-, se presentará en el año 2024 (escenario base); se advierte que la sociedad costarricense,

14 En julio de 2015, el analista actuarial argentino Eduardo Melinsky presentó un estudio que arrojó conclusiones similares a las indicadas en el Informe de la UCR, pero ese informe fue desechado por la CCSS, por no contar con todas las herramientas en el modelo actuarial requeridas por la ciencia y la técnica, entre otros aspectos. 
a más tardar en los próximos dos años, debe ajustar los parámetros del RIVM para restaurar la sostenibilidad económica del mismo.

\section{PROCEDIMIENTO METODOLÓGICO}

Dentro de la problemática que afronta el sistema de pensiones y, en particular, el RIVM, en este documento se presentan los resultados de un análisis empírico, desde un enfoque macroeconómico, sobre las opciones que tienen las autoridades públicas para controlar el crecimiento del gasto en pensiones del RIVM como proporción del Producto Interno Bruto (PIB), en aras de buscar la sostenibilidad económica de este régimen de pensiones.

Como se indicó en los apartados anteriores, el Programa Estado de la Nación desde el 2005 había identificado cuatro factores que incidían directamente sobre la situación financiera del RIVM. Estos elementos son: la situación demográfica, la dinámica del mercado laboral, aspectos de diseño del régimen y niveles de eficiencia administrativa (Programa Estado de la Nación, 2005).

En esa misma línea, Conde-Ruiz (2017) propuso analizar la evolución del gasto pensiones a través del estudio de los determinantes fundamentales de ese gasto agregado. Para ello, el autor plantea descomponer el gasto en pensiones como porcentaje del PIB en tres factores básicos: factor demográfico, factor mercado de trabajo y el factor institucional; este último puede descomponerse en dos factores adicionales que se denominan Elegibilidad y Generosidad. Esta descomposición del gasto en pensiones es congruente con lo señalado por el Programa Estado de la Nación en el 2005 y este estudio lo utiliza como base en la modelización matemática.

Para aplicar el enfoque descrito por Conde-Ruiz (2017), se desarrolla un modelo econométrico que desagrega el gasto total en pensiones del RIVM en proporción al PIB, en cuatro componentes. Posteriormente, con los datos disponibles para el período 2000-2017, se evalúa empíricamente el modelo utilizando el método de Mínimos Cuadrados Ordinarios (MCO) y así determinar los coeficientes asociados a cada componente o factor.

El gasto en pensiones como porcentaje del PIB se puede desagregar en la siguiente entidad contable: 


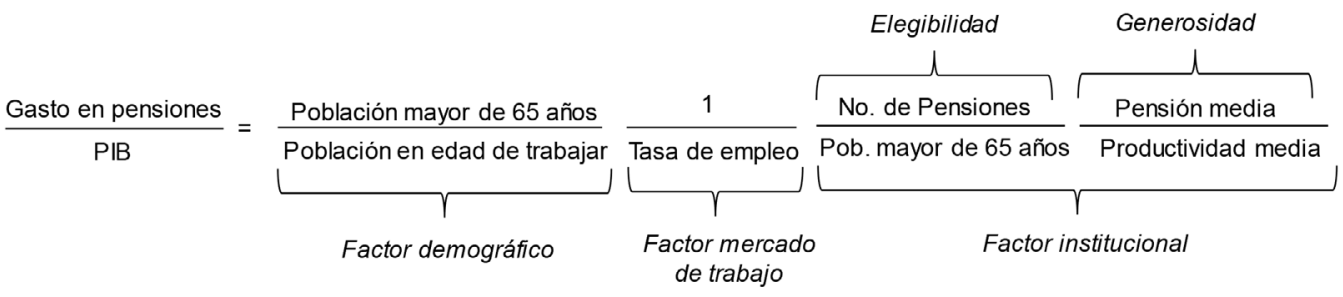

Dentro de este contexto, el factor demográfico constituye la tasa de dependencia que se calcula por el número de personas en edad de pensión, dividida por la población en edad de trabajar. Entre mayor sea la tasa de dependencia, mayor será el gasto en pensiones como porcentaje del PIB.

El factor mercado de trabajo es la inversa de la tasa de empleo (población en edad de trabajar que cuenta con trabajo), de forma que cuanto menor sea la tasa de empleo (o mayor la tasa de desempleo), mayor será el gasto en pensiones en relación con el PIB.

El factor de elegibilidad se define como el cociente entre el número de pensiones otorgado dividido entre la cantidad de personas en edad de jubilación. Este factor se incrementa conforme aumente la tasa de cobertura del régimen.

El factor de generosidad consiste en la razón de pensión media entre productividad media (PIB por ocupado), de manera que entre mayor sea la pensión media en relación con la productividad promedio, mayor será el gasto en pensiones.

Los factores de elegibilidad y generosidad conforman el factor institucional que depende de la normativa que rige al sistema de pensiones y que se ve afectado por las reformas que adopten las autoridades. En este sentido, el gasto en relación al PIB dependerá de las políticas de acceso a la pensión, de los cambios en la productividad de la economía y de cómo estos cambios se trasladan a las pensiones.

Para la estimación del modelo se contó una serie de datos para el período 2000-2017 que contiene las cifras del PIB, tasa de inflación, población económicamente activa (PEA), población total, cobertura del RIVM sobre 
la PEA, población mayor de 65 años, tasa de desempleo abierto, número de pensiones otorgadas por el RIVM y pensión media del RIVM. Esta información provino de diversas fuentes, como el Instituto Nacional de Estadísticas y Censos (INEC), Banco Central de Costa Rica (BCR), Caja Costarricense de Seguro Social (CCSS) y el Estudio actuarial del régimen de IVM realizado por Arias, Barboza y Ramírez (2016) de la Escuela de Matemática de la Universidad de Costa Rica.

La Figura 2 muestra la evolución en el tiempo de la razón del gasto en pensiones del RIVM respecto al PIB para el período analizado. Se observa cómo el gasto en pensiones del RIVM como porcentaje del PIB ha presentado una tendencia creciente, la cual se acelera a partir del año 2007.

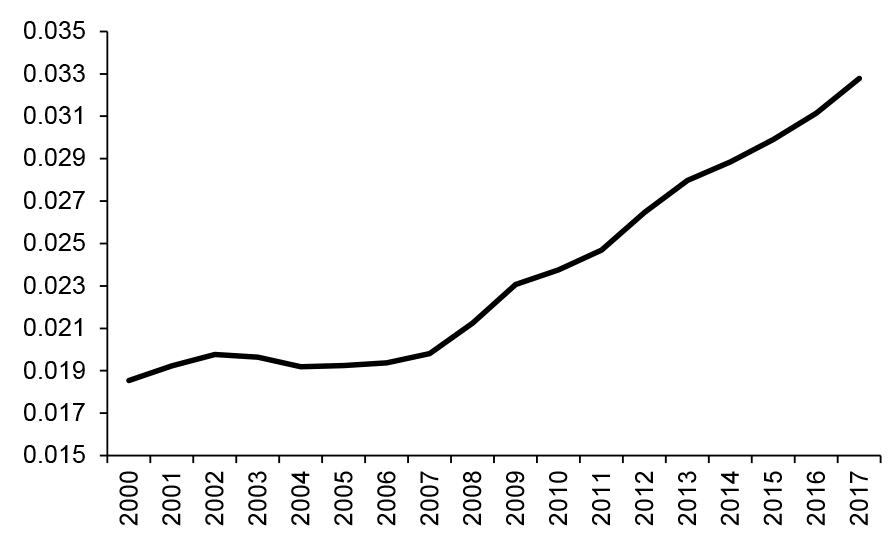

Figura 2. Evolución de la razón gasto en pensiones del RIVM a PIB (20002017).

La Figura 3 muestra el comportamiento de las variables dependientes para el período analizado. 


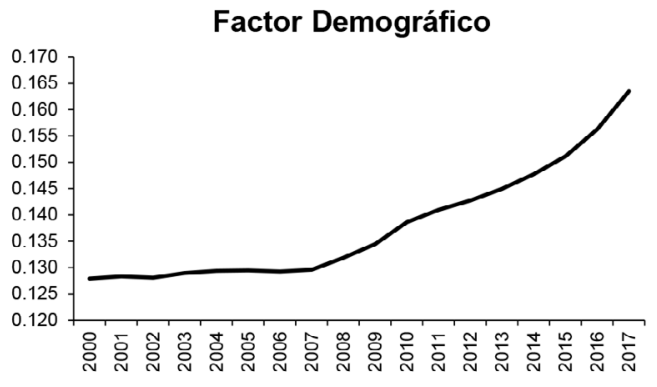

Factor Elegibilidad

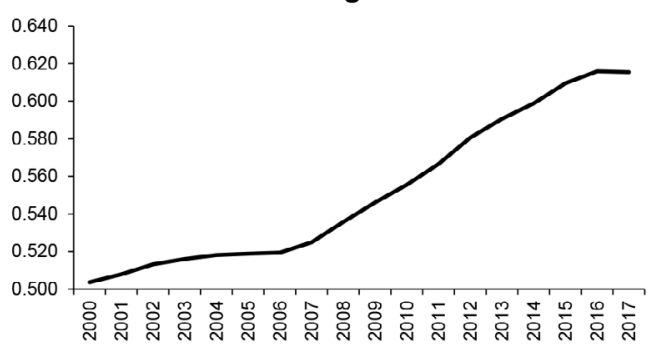

Factor Mercado Trabajo

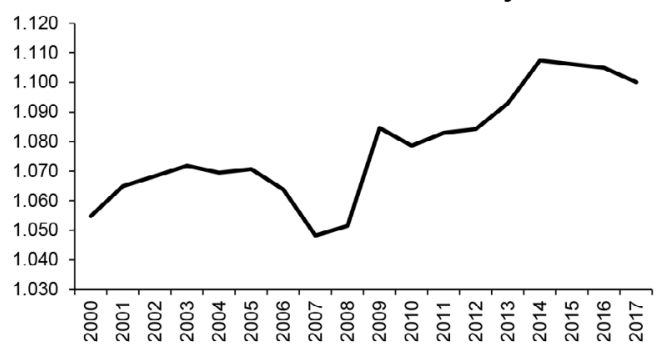

Factor Generosidad

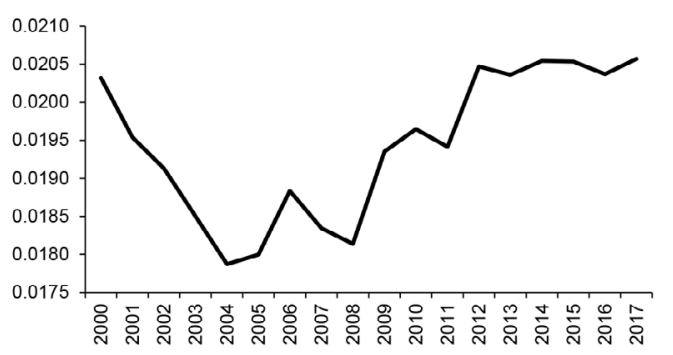

Figura 3. Evolución de las variables: factor demográfico, factor de mercado de trabajo, factor de elegibilidad y factor generosidad (2000-2017)

La Figura 3 muestra el crecimiento sostenido que ha experimentado el factor demográfico en el período analizado. La población mayor de 65 años ha crecido de forma más pronunciada que la población en edad de trabajar o PEA.

Por su parte, la evolución del factor de mercado de trabajo ha sido irregular, aunque muestra una tendencia creciente para todo el período de análisis. La serie presenta una reducción a partir del año 2005 para volver a crecer a partir del año 2008. Esta variable se incrementa según aumente la tasa de desempleo o, lo contrario, se reduce conforme se incremente la tasa de empleo, de manera que se observa un crecimiento sostenido de ese factor a partir del año 2008 debido al aumento en la tasa de desempleo de la economía. 
El factor de elegibilidad ha crecido constantemente en el período analizado, lo que muestra que cada año aumenta la cobertura del RIVM en atención a la población de 65 años o más.

Finalmente, el factor de generosidad, que se define como la pensión media sobre la productividad media, presenta un comportamiento variable. Es decreciente para los primeros años de la serie, lo que muestra que la pensión media del RIVM había crecido por debajo del aumento de la productividad de la economía; sin embargo, a partir de ese año se observa una tendencia creciente (aunque irregular), lo cual indica que la pensión media se ha incrementado a una tasa mayor que el aumento de la productividad en la economía.

Con base en la metodología aplicada, la razón entre la variable dependiente, gasto en pensiones del RIVM al PIB y las variables independientes descritas, se puede expresar de la siguiente forma:

$$
\mathrm{G} / \mathrm{PIB}=\mathrm{f}(\mathrm{FD}, \mathrm{FMT}, \mathrm{ELEG}, \mathrm{GEN})
$$

Donde:G/PIB: $\quad$ Gasto en pensiones del RIVM como proporción del PIB.

FD: $\quad$ Factor Demográfico.

FMT: Factor Mercado de trabajo.

ELEG: Exigibilidad.

GENE: Generosidad.

Para expresar la relación entre la variable dependiente, G/PIB y las variables independientes, factores o determinantes del gasto, se utilizó la siguiente especificación funcional:

$$
\mathrm{G} / \mathrm{PIB}=\alpha_{0} \mathrm{FD}^{\alpha 1} \mathrm{FMT}^{\alpha 2} \mathrm{ELEG}^{\alpha 3} \mathrm{GENE}^{\alpha 4}
$$

Esta forma funcional, mediante derivación matemática, proporciona las elasticidades constantes $\left(\alpha_{i}\right)$ de cada variable dependiente con respecto a la variable independiente. De forma que, una alta elasticidad indicaría que un cambio en la variable independiente respectiva tiene un gran impacto 
sobre el Gasto en pensiones como proporción del PIB (G/PIB), lo contrario ocurriría en caso de una baja elasticidad. ${ }^{15}$

Para el proceso de estimación, la ecuación (2) se puede expresar, en forma alternativa, utilizando logaritmo natural (In) como:

$$
\ln (\mathrm{G} / \mathrm{PIB})=\alpha_{0}^{*}+\alpha_{1} \ln (\mathrm{FD})+\alpha_{2} \ln (F M T)+\alpha_{3} \ln (E L E G)+\alpha_{4} \ln (\mathrm{GENE})
$$

En este caso, $\alpha_{0}^{*}=\ln \left(\alpha_{0}\right)$

La estimación de los parámetros de la forma funcional se realizó mediante el proceso de regresión lineal utilizando el método de Mínimos cuadrados ordinarios (MCO) y la ecuación antes descrita. La aplicación del método de MCO y las pruebas estadísticas se realizaron empleando el paquete o software computacional SPSS versión 25. La estimación de la forma funcional (3) mediante regresión por mínimos cuadrados ordinarios se presenta en la Tabla 2.

El ajuste lineal presentado en la Tabla 1 relaciona satisfactoriamente la razón del Gasto en Pensiones del RIVM al PIB con los cuatro factores básicos descritos; Factor Demográfico, Factor de Mercado de Trabajo, la Elegibilidad y la Generosidad.

Los coeficientes de determinación o $\mathrm{R}^{2}$, simple y ajustado, son superiores a $99 \%$, lo cual indica que el modelo estimado explica más del $99 \%$ de la variación en la razón gasto en pensiones del RIVM a PIB. Asimismo, tres de los coeficientes asociados a las variables independientes resultaron significativos al 0.05. No obstante, el coeficiente de la variable Factor Mercado de Trabajo no resultó significativo. El valor del intercepto o constante es negativo y aunque tiene una significancia estadística alta (superior al 0.01), no posee interpretación social viable.

$15 \mathrm{El}$ coeficiente de elasticidad es una medida de la fuerza relativa con que responde una variable dependiente ante cambios de uno por ciento en las variables independientes (Mankiw, 2012). 
Tabla 1

Gasto en pensiones del RIVM en relación al PIB:

Ajuste por Mínimos Cuadrados Ordinarios

\begin{tabular}{l|c|c|c|c|}
\hline \multicolumn{1}{|c|}{ Variable } & Coeficiente & $\begin{array}{c}\text { Error } \\
\text { estándar }\end{array}$ & Estadístico-t & Probabilidad \\
\hline Constante & -9.984 & 1.993 & -5.009 & 0.000 \\
\hline Factor Demográfico & 0.631 & 0.219 & 2.876 & 0.013 \\
\hline Factor Mercado de Trabajo & 0.352 & 0.501 & 0.703 & 0.495 \\
\hline Elegibilidad & 1.834 & 0.247 & 7.433 & 0.000 \\
\hline Generosidad & 0.261 & 0.116 & 2.260 & 0.042 \\
\hline R-cuadrada & 0.995 & Durbin-Watson & 1.192 \\
\hline R-cuadrada ajustada & 0.993 & \\
\hline Error estándar de la regresió & 0.01606 & & \\
\hline Estadístico F & 626.570 \\
\hline Prob(Estadístico F) & 0.0000 & & \\
\hline
\end{tabular}

Nota: Las variables se encuentran expresadas en logaritmo natural (Ln).

Por su parte, el estadístico F, que permite contrastar la capacidad explicativa conjunta de las variables introducidas en el modelo, es significativo al 0.01; con lo cual, el modelo constituye una representación adecuada del fenómeno que se está analizando.

El estadístico Durbin-Watson (DW) permite evaluar la presencia del fenómeno de autocorrelación en la estimación. En este caso, al ser el DW igual 1.231 y al aplicar la tabla de Savin y White resulta que la prueba no es concluyente (Gujarati \& Porter, 2010).

El hecho de que el coeficiente de la variable FMT no sea significativo podría ser un síntoma de multicolinealidad. Para evaluar esta situación Gujarati y Porter (2010), indican que no existe un método único: "Lo que se tiene en realidad son ciertas reglas prácticas, algunas formales y otras no formales, pero todas reglas prácticas" (p. 337).

La Prueba tradicional se realiza evaluando la bondad del ajuste y la significancia estadística de los coeficientes estimados. Según esta prueba, 
ante la presencia de multicolinealidad, es frecuente hallar junto a estadísticos $\mathrm{t}$ no significativos, contrastes $\mathrm{F}$ plenamente aceptables y $\mathrm{R}^{2}$ elevados. Según el criterio descrito, al revisar el ajuste presentado en la tabla 1 no existe evidencia contundente de multicolinealidad.

Como uno de los factores resultó no significativo (FMT), se optó por corregir ese problema eliminando la variable Mercado de Trabajo y se procedió a correr nuevamente la regresión lineal. El modelo resultante se ha denominado modelo 2 .

El modelo 2 a evaluar mediante el método de mínimos cuadrados es el siguiente:

$$
G / P I B=f(F D, E L E G, G E N)
$$

Donde: G/PIB: Gasto en pensiones del RIVM como proporción del PIB.

FD: $\quad$ Factor Demográfico.

ELEG: Exigibilidad.

GENE: Generosidad.

La especificación de la ecuación (4) es la siguiente forma:

$$
\mathrm{G} / \mathrm{PIB}=\alpha_{0} \mathrm{FD}^{\alpha 1} \mathrm{ELEG}^{\mathrm{\alpha} 2} \mathrm{GENE}^{\mathrm{\alpha} 3}
$$

Para efectos de estimación, se utilizará la siguiente expresión en forma logarítmica:

$$
\begin{aligned}
& \ln (G / P I B)=\alpha_{0}^{*}+\alpha_{1} \ln (F D)+\alpha_{2} \ln (E L E G)+\alpha_{3} \ln (G E N E) \\
& \text { En este caso, } \alpha_{0}^{*}=\ln \left(\alpha_{0}\right)
\end{aligned}
$$

La estimación de la forma funcional (6) mediante regresión por mínimos cuadrados ordinarios se presenta en la Tabla 2. 
Tabla 2

Gasto en pensiones del RIVM en relación al PIB:

Ajuste por Mínimos Cuadrados Ordinarios

\begin{tabular}{l|c|c|c|c|}
\hline \multicolumn{1}{|c|}{ Variable } & Coeficiente & $\begin{array}{c}\text { Error } \\
\text { estándar }\end{array}$ & Estadístico-t & Probabilidad \\
\hline Constante & -8.613 & 0.396 & -21.730 & 0.000 \\
\hline Factor Demográfico & 0.633 & 0.215 & 2.941 & 0.011 \\
\hline Elegibilidad & 1.898 & 0.225 & 8.433 & 0.000 \\
\hline Generosidad & 0.278 & 0.111 & 2.513 & 0.025 \\
\hline R-cuadrada & 0.995 & Durbin-Watson & 1.256 \\
\hline R-cuadrada ajustada & 0.993 & \\
\hline Error estándar de la regresióı & 0.01577 & \\
\hline Estadístico F & 866.587 \\
\hline Prob(Estadístico F) & 0.0000 \\
\hline
\end{tabular}

Nota: Las variables se encuentran expresadas en logaritmo natural (LN).

De la estimación anterior (Tabla 2), se observa que al excluir el factor mercado de trabajo, el modelo mejora notoriamente; los coeficientes de determinación simple y ajustado son superiores al $99 \%$ y todos los coeficientes de la regresión son significativos al .05. Asimismo, la prueba $\mathrm{F}$ resultó significativa al .01. Estos resultados indican que el modelo constituye una representación adecuada del fenómeno analizado.

En el análisis de la presencia de multicolinealidad, la prueba tradicional concluye ausencia de ese fenómeno; sin embargo, la prueba de Durbin-Watson, valorada según la tabla de Savin y White, no es concluyente $y$, por tanto, no permite afirmar o descartar la presencia de autocorrelación.

El resultado anterior, indica que, para el período analizado, el gasto en pensiones del RIVM como porcentaje del PIB se explica por el factor Demográfico, el factor de Elegibilidad y el factor de Generosidad, según se muestra a continuación. 


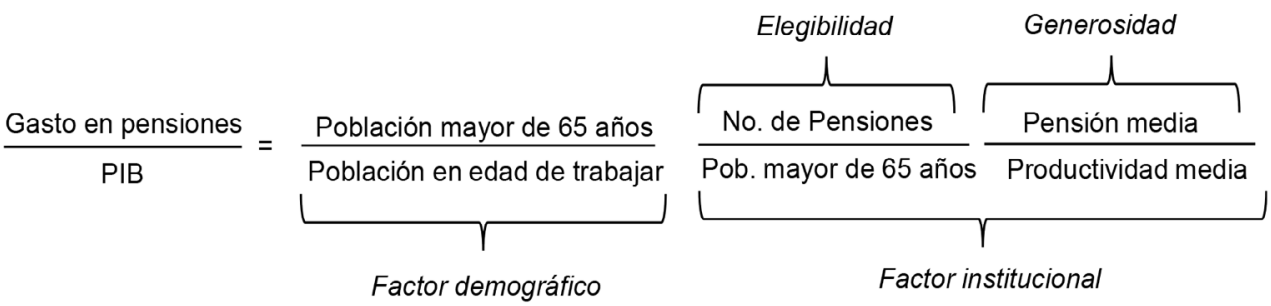

La Figura 4 presenta la evolución de la razón G/PIB real o efectiva y la razón estimada mediante el modelo de regresión para el período 2000-2017. Se observa cómo la estimación del G/PIB lograda mediante el modelo econométrico, provee una buena representación del dato real.

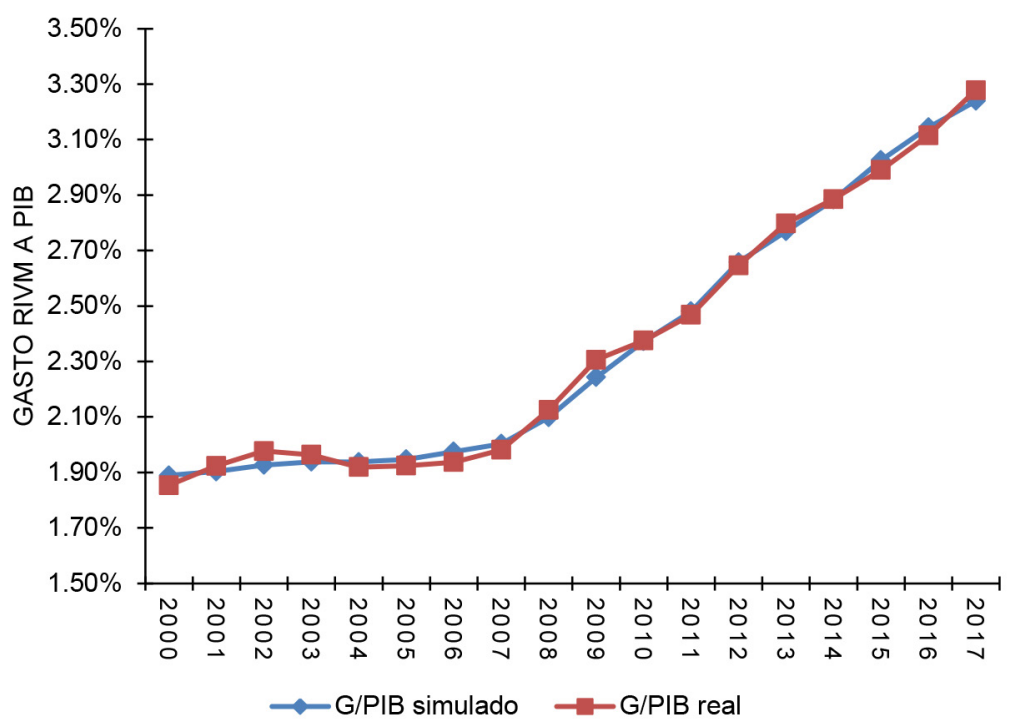

Figura 4. Razón gasto en pensiones del RIVM en relación con el PIB, comparación de datos reales o efectivos y datos estimados por el modelo econométrico (2000-2017) 


\section{RESULTADOS Y DISCUSIÓN}

El modelo econométrico desarrollado provee las elasticidades de las variables explicativas (Factor Demográfico, Mercado de Trabajo, Elegibilidad y Generosidad) en relación con la variable explicada (G/PIB). Los coeficientes de elasticidad de ambas estimaciones (modelo 1 y modelo 2) se resumen en la Tabla 3.

Según puede observarse, en ambos modelos (modelo 1 y modelo 2), la elasticidad más alta corresponde al factor Elegibilidad y supera el valor de uno. Esta circunstancia implica que la relación entre las variables es elástica; es decir, cada cambio porcentual (1\%) en el factor Elegibilidad conduce a una respuesta más que proporcional en la razón de gasto, para el modelo 2 , el cambio en la razón de gasto es de $1.898 \%$.

El valor del coeficiente de elasticidad del factor Elegibilidad (1.898) y el hecho de que la variable se defina como el cociente entre el número de pensiones del RIVM entre la población mayor de 65 años, conduce a considerar la importancia dentro del gasto del efecto de los incrementos en la cobertura del régimen sobre la población mayor de 65 años. Entre mayor sea el número de pensiones que otorgue el régimen en relación con la población adulta mayor de 65 años, mayor será el incremento en el gasto del RIVM como porcentaje del PIB.

\section{Tabla 3}

Gasto en pensiones del RIVM en relación al PIB:

Ajuste por Mínimos Cuadrados Ordinarios

\begin{tabular}{l|c|l|c|l}
\hline \multirow{2}{*}{ Factor } & \multicolumn{2}{c|}{ Modelo 1 } & \multicolumn{2}{c}{ Modelo 2 } \\
\cline { 2 - 5 } & Coeficiente & Tipo de elasticiad & Coeficiente & Tipo de elasticiad \\
\hline Demográfico & $0.631^{*}$ & inelástico & $0.633^{* /}$ & inelástico \\
\hline Mercado de trabajo & 0.352 & inelástico & & \\
\hline Elegibilidad & $1.834^{* /}$ & elástico & $1.898^{* /}$ & elástico \\
\hline Generosidad & $0.261^{* /}$ & inelástico & $0.278^{* /}$ & inelástico \\
\hline
\end{tabular}

*/ Significativo al nivel de 0,05.

Para el caso de la política pública, las autoridades solo pueden influir en la variable generosidad a través del número de pensiones a otorgar, dado 
que la cantidad de personas en edad para jubilarse responde a aspectos demográficos y no socioeconómicos. Por tanto, para compensar el efecto expansivo que tiene esta variable, las autoridades deberán establecer un nivel de cobertura del régimen acorde con el crecimiento futuro de la población adulta mayor, de manera que el incremento en el factor de elegibilidad sea lo menor posible. Asimismo, una medida para contener el número de pensiones y reducir la razón gasto a PIB consiste en aumentar la edad de retiro de forma congruente con el aumento en la esperanza de vida.

Por su parte, para el factor demográfico y el de generosidad, la elasticidad resultó inferior a uno, es decir, inelásticas. Esto implica que los cambios en estas variables dependientes tienen un efecto proporcionalmente menor sobre la razón G/PIB.

Considerando las proyecciones del INEC (2013) en cuanto al crecimiento de población mayor de 65 años y la PEA, el crecimiento del factor demográfico, ceteris paribus, impactaría el crecimiento del gasto en relación al PIB de la siguiente forma:

\begin{tabular}{lll}
\hline AÑo & $\begin{array}{l}\text { Factor } \\
\text { demográfico }\end{array}$ & G/PIB \\
\hline 2017 & 0.16347 & $3.24 \%$ \\
2020 & 0.12777 & $2.77 \%$ \\
2030 & 0.19167 & $3.58 \%$ \\
2040 & 0.24734 & $4.21 \%$ \\
2050 & 0.32579 & $5.01 \%$ \\
\hline
\end{tabular}

Por tanto, si se cumple el escenario demográfico del INEC, —al considerar únicamente el aumento en el factor demográfico-, la razón G/PIB, pasaría de $3.24 \%$ en el año 2017 a 5\% para el año 2050.

El factor generosidad (GENE) que se define como la pensión media del RIVM dividida entre la productividad media (esta última calculada como el PIB per cápita) también presenta un coeficiente inelástico $(0.278$, según el modelo 2), de manera que los cambios en este variable impactan menos que proporcionalmente a la razón G/PIB. 
Para efectos de política pública, esta variable puede reducirse si se incrementa la productividad media por trabajador o se reduce la pensión media del RIVM. En las simulaciones realizadas un aumento del $10 \%$ en la productividad media del trabajador, ceteris paribus, redujo la razón G/PIB en 0.08 puntos; es decir, se reduce en un $2.61 \%$. En el caso de los aumentos en la productividad, al considerar que estos deberían impactar la pensión media recibida por el trabajador, la reducción en la razón G/PIB prevista anteriormente sería menor, dado que se estarían incrementando tanto el numerador como el denominador de la variable generosidad. Por tanto, los aumentos en la productividad contribuyen con reducir el gasto en pensiones del RIVM en relación al PIB, cuando los mismos no se trasladan proporcionalmente de forma instantánea y permanente a la pensión media.

El factor generosidad también puede reducirse si se disminuye la pensión media del RIVM. Para analizar este efecto, se simuló una reducción del $10 \%$ en la pensión media, ceteris paribus. Este cambio hizo que la razón G/PIB se reduce en 0,09 puntos, es decir, ser reduce en $2.9 \%$. De esta forma, se observa que una opción para disminuir el factor generosidad consiste en reducir la tasa de sustitución de las pensiones, de manera que se contenga el crecimiento del numerador da la variable. Sin embargo, la política pública busca incrementar 0 , al menos no reducir, la tasa de sustitución para asegurar a la persona jubilada un nivel de vida digno.

Finalmente, como se indicó, la variable mercado de trabajo (FMT) no resultó significativa en el modelo 1, por lo cual se eliminó en la segunda corrida del modelo. Cabe recordar que esta variable se define como la inversa de la tasa de ocupación, que a su vez se calcula como el complemento de la tasa de desempleo abierto.

Por tanto, según la definición para que dicho factor se reduzca debe aumentar la tasa de empleo en la economía. Sin embargo, al eliminarla y estimar el modelo 2 sin ella, mejoró notablemente la estimación de la ecuación, lo que lleva a pensar que dicha variable no contribuye en la explicación del fenómeno del gasto del RIVM en relación con el PIB.

Una posible explicación de este fenómeno puede hallarse en el carácter de reparto del RIVM, pues por el lado del gasto, hasta cierto punto la pensión media del régimen es independiente de los ingresos que reciben los beneficiarios durante su vida laboral activa. En un análisis de 
sostenibilidad del RIVM que incluya el lado del ingreso, dicha variable debería ser fundamental.

Los anteriores resultados se consideran relevantes para la política de contención del gasto en pensiones, dado que muestran la importancia que poseen los factores de elegibilidad y generosidad sobre el gasto en pensiones del RIVM como proporción del PIB. Al considerar estos dos impactos (exigibilidad y generosidad), se observa que, la suma de estas elasticidades es $2.176 \%$, valor que denota un impacto más que proporcional sobre el gasto relativo en pensiones.

Lo anterior muestra que para contener el crecimiento del gasto en pensiones del RIVM como porcentaje del PIB se debe centrar la atención en la cobertura del régimen en relación con la población mayor de 65 años y el valor de la pensión media en relación con la productividad de la mano de obra, ambos son factores institucionales, susceptibles de modificación mediante la política pública. Cabe indicar que el factor demográfico es importante, pero su evolución, en el mediano y corto plazo, no depende de la política pública.

\section{CONCLUSIONES}

Para mantener controlado el gasto en pensiones del RIVM como porcentaje del PIB, según la modelización realizada en este estudio, se hace necesario reducir la tasa de desempleo abierto y aumentar la productividad del trabajo. Desde el punto de vista del factor de Elegibilidad, se debe controlar el número de pensiones a otorgar de manera que deben contenerse 0 eliminarse las posibilidades de pensión adelantada e incentivar a los trabajadores a posponer su jubilación. Asimismo, como medida complementaria se puede establecer una tasa de cotización para las pensiones otorgadas.

Desde el punto de vista de la variable de Generosidad, las pensiones medias se deben revalorizar de forma conservadora de manera que esta revaloración no supere la tasa de crecimiento de la productividad de la mano de obra.

Cabe recordar que este estudio exploró las posibilidades de contención del gasto desde el punto de vista macroeconómico y no abordó el problema de sostenibilidad financiera, desde el lado de los ingresos. Dichos aspectos 
podrían evaluar el aumento en las cuotas de cotización, opciones de inversión de los fondos de reserva para incrementar la rentabilidad de las inversiones y el establecimiento de otros ingresos como las cotizaciones sobre el capital, el consumo y el establecimiento de tributos para fortalecer el fondo de reserva de los sistemas de pensiones.

\section{REFERENCIAS}

Arias, R., Barboza L., \& Ramírez J. (2016). Estudio actuarial del seguro de invalidez, vejez y muerte administrado por la caja costarricense de seguro social. Escuela de Matemática. Costa Rica: Universidad de Costa Rica.

Arquiola, E. (1995). La vejez a debate. Análisis histórico de la situación socioeconómica de la vejez en la actualidad. Madrid, España: CSIC.

Avendaño, M. (enero 22 de enero 2017). Ajustes a largo plazo al IVM. Semanario El Financiero.

Banco Mundial. (1997). Averting the Old Age crisis: policies to protect the old and promote growth. Oxford U. Press.

Banco Mundial. (2015). Perspectivas Económicas Mundiales. EE.UU.: BM.

Conde-Ruiz, J. (2017). Medidas para restaurar (o no) la sostenibilidad financiera de las pensiones. España, Fedea Policy Papers -2017/04.

Gujarati, D. \& Porter, D. (2010). Econometría. (5 $5^{a}$ ed.). México: McGraw Hill.

Instituto Nacional de Estadística y Censos. (2003). Encuesta Nacional de Hogares. Costa Rica: INEC.

Instituto Nacional de Estadística y Censos. (2013). Estimaciones y Proyecciones de Población por sexo y edad: 1950-2050. Costa Rica: INEC.

Kibut, I. (2004). La sostenibilidad Financiera del Régimen de Invalidez, Vejez y Muerte en el periodo 2000-2025. Diagnóstico. Tesis de Maestría. Costa Rica: UNED. 
Ley de Protección al Trabajador, No. 7983 del 16 de febrero de 2000. Alcance 11 a La Gaceta 35 del 18 de febrero de 2000.

Mankiw, G. (2012). Principios de economía. (6 $6^{\mathrm{a}}$ ed.). Cengage Learning. Martínez, J. (2005). Reformas recientes de las pensiones en Costa Rica: Avances hacia una mayor sostenibilidad financiera, acceso y progresividad del primer pilar de pensiones. San José: Programa Estado de la Nación.

Martínez, M., Polo, M., Carrazco, B. (2002). Visión histórica del concepto de vejez desde la Edad Media. Revista Cultura de los Cuidadis, VI(11), 40-46.

Mesa-Lago, C. (2012). Sistema de protección social en América Latina y el Caribe. Chile: CEPAL.

MIDEPLAN. (2016). Costa Rica: Estado de las pensiones: Régimen de Invalidez, Vejez y Muerte. Unidad Análisis Prospectivo. Costa Rica: MIDEPLAN.

MIDEPLAN. (2017). Costa Rica: Prospectiva en cambio demográfico al 2045. Unidad de Análisis Prospectivo. Costa Rica: MIDEPLAN.

Nathal. (2008). Informe Final de la valuación actuarial practicada al Régimen de Invalidez, Vejez y Muerte de la Caja Costarricense del Seguro Social.

Péne, D. (1999). La civilización de los jubilados. Madrid: Ediciones Encuentros.

Programa Estado de la Nación. (2005). Undécimo Informe Estado de la Nación en Desarrollo Humano Sostenible. San José: Programa Estado de la Nación.

Samuelson, P. (1958). An exact cosumption-loan model of interest with or witout the social contrivance of money. Journal of Political Economics.

Sauma, P. (2013). Situación y características del sistema de pensiones al 2012. San José: Programa Estado de la Nación. 
Torres, C. (2015). Valuación actuarial de largo plazo del Seguro de Invalidez, Vejez y Muerte. San José, Costa Rica: Caja Costarricense de Seguro Social.

WorldLife (2017). Pirámide de población de Costa Rica. EE.UU: LEDUCMEDIA. 